\title{
HIV prevalence among TB patients attending DOTS centres in rural Haryana, India
}

\author{
Ravi Kumar Balu*, Sanjay Rai, Shashi Kant, Krishnan Anand, Lalit Dar, Urvashi Singh \\ From $16^{\text {th }}$ International Symposium on HIV and Emerging Infectious Diseases \\ Marseille, France. 24-26 March 2010
}

\section{Background}

This study was done to estimate the prevalence of HIV infection among TB patients; and the presence of HIV related risk behavior among these TB patients attending DOTS centres in Ballabgarh, Haryana, India.

\section{Methods}

The study was carried out in two DOTS centres of Ballabgarh Tehsil of district Faridabad, Haryana. It was a health facility based cross sectional survey. Study subjects were all TB patients (Pulmonary and Extra Pulmonary) who were registered for DOTS. Data was collected from January 2007 to June 2008. We enrolled 413 patients. Eligible subjects were informed about the study objectives and written consent was obtained. Interview schedule was used for data collection. All patients were offered free Liver Function Test. Unlinked anonymous testing on aliquot of LFT blood samples was performed after removing all identifiers. HIV testing was done using three $\mathrm{E} / \mathrm{R} / \mathrm{S}$

\section{Results}

Four hundred and thirteen TB patients were interviewed and blood samples could be obtained from 368 patients (89.1\%). Among them four samples got contaminated and labels of ten samples was lost during the transportation. Finally off the 354 samples tested two were found HIV sero reactive. Prevalence of HIV among TB was 0.56\% (95\% CI 0.068-2.02).

Of the 315 (76.3\%) who ever had sexual intercourse, 289 (91.7\%) reported sex with spouse/regular partner, 20 (6.4\%) with non regular partner, five with female sex worker and one had with multiple partner. Three (11.5\%) subjects used condoms regularly, eight (30.8\%) used occasionally and 15 (57.7\%) never used condom

\footnotetext{
* Correspondence: beravi4@hotmail.com

All India Institute of Medical Sciences, New Delhi, India
}

$(\mathrm{n}=26)$. Among all married patients $(\mathrm{n}=293), 13(4 \%)$ had sex outside marriage. Six patients had a paid sex $(n=13)$. One patient each reported of having anogenital ulcer and intravenous drug usage in last one year.

\section{Discussion}

HIV prevalence was low and similar to the rate observed among pregnant women $(0.13 \%)$ who could be considered as proxy to general low risk population. HIV risk behavior among TB patients was low and comparable to general population rate observed in a state wide behaviour survey. Low risk behaviour contributed to low HIV prevalence among the study population.

Published: 11 May 2010

doi:10.1186/1742-4690-7-S1-P124

Cite this article as: Balu et al:: HIV prevalence among TB patients attending DOTS centres in rural Haryana, India. Retrovirology 2010 7(Suppl 1):P124.

\section{Submit your next manuscript to BioMed Central and take full advantage of: \\ - Convenient online submission \\ - Thorough peer review \\ - No space constraints or color figure charges \\ - Immediate publication on acceptance \\ - Inclusion in PubMed, CAS, Scopus and Google Scholar \\ - Research which is freely available for redistribution \\ Submit your manuscript at www.biomedcentral.com/submit}

